\title{
Article \\ Ready Teacher One: Virtual and Augmented Reality Online Professional Development for K-12 School Teachers
}

\author{
Stylianos Mystakidis ${ }^{1,2, *(D)}$, Maria Fragkaki ${ }^{3,4}$ and Giorgos Filippousis ${ }^{2}(\mathbb{D}$ \\ 1 School of Natural Sciences, University of Patras, Rion, 26504 Patras, Greece \\ 2 School of Humanities, Hellenic Open University, 26335 Patras, Greece; filvisg@outlook.com \\ 3 Department of Educational Sciences and Early Childhood Education, University of Patras, Rion, \\ 26504 Patras, Greece; fragakim@upatras.gr \\ 4 Faculty of Economics and Management, Open University of Cyprus, Nicosia 2220, Cyprus \\ * Correspondence: smyst@upatras.gr
}

check for updates

Citation: Mystakidis, S.; Fragkaki, M.; Filippousis, G. Ready Teacher One: Virtual and Augmented Reality Online Professional Development for K-12 School Teachers. Computers 2021, 10, 134. https://doi.org/10.3390/ computers10100134

Academic Editor: Paolo Bellavista

Received: 30 August 2021

Accepted: 12 October 2021

Published: 17 October 2021

Publisher's Note: MDPI stays neutral with regard to jurisdictional claims in published maps and institutional affiliations.

Copyright: (c) 2021 by the authors. Licensee MDPI, Basel, Switzerland. This article is an open access article distributed under the terms and conditions of the Creative Commons Attribution (CC BY) license (https:/ / creativecommons.org/licenses/by/ $4.0 /)$.

\begin{abstract}
Augmented reality (AR) and virtual reality (VR) are two technologies with the potential to enhance learning quality by activating episodic student memory. In this manuscript we outline the pedagogical benefits of AR and VR as well as the rationale, design, development, and pilot evaluation results from an in-service teacher online professional development program (OPD) on AR and VR linked with research activities. More specifically, we examined the "Augmented and Virtual Reality in Teaching and Learning" OPD course aimed at K-12 educators in a European country combining pedagogically informed methods such as inquiry-based learning and digital storytelling. Findings from a mixed-method research using questionnaires and focus groups indicate that AR- and VR-based pedagogical scenarios can be integrated effectively into everyday school teaching practice. The study also outlines implications and limitations that policy makers, education leaders, and educators need to consider for efficient institution-wide deployment of AR and VR technologies.
\end{abstract}

Keywords: augmented reality; virtual reality; teacher professional development; online professional development; distance learning; flipped learning; research-based education; K-12

\section{Introduction}

"It was also a lot easier for online teachers to hold their students' attention, because here in the OASIS, the classrooms were like holodecks. Teachers could take their students on a virtual field trip every day, without ever leaving the school grounds" (Ernest Cline, Ready Player One, p. 47).

Virtual reality (VR), augmented reality (AR), and mixed reality (MR) are associated with the fourth transformational wave of innovation in computing platforms [1]. The previous three innovation waves brought computers, the internet, and mobile devices to mainstream adoption. These fundamental digital technologies had a profound impact on everyday life, communication, interaction, work, and education. VR, AR, and MR can be encapsulated in the technological umbrella term extended reality or cross reality $(X R)$ [2,3]. In all facets of XR, information is represented and projected in digital, electronic environments.

Teacher digital competence or digital literacy is essential in the knowledge society [4]. These skills are crucial both for their teaching performance optimization, professional career progress as well as for the successful preparation of students for their future roles in the society and the workplace [5]. Digital literacy is not limited to technological aptitude and management of ICT equipment and software but includes the meaningful integration with pedagogy as highlighted in frameworks such as the technological pedagogical and content knowledge TPACK model [6]. Cornerstones of digital teacher competencies-beyond teaching, learning, and assessment-include pedagogical knowledge, communications skills, and professional engagement in teacher communities of practice [7]. In the European Framework for the Digital Competence of Educators, professional engagement of teachers 
includes critical self-reflection and participation in continuous professional development [8]. Data from the Programme for International Student Assessment (PISA) associate teachers professional development opportunities along with factors such as initial motivation, school climate, teacher collaboration, and availability of resources with teacher satisfaction and success [9]. Teacher professional development can take many formats such as courses, workshops, conferences, field trips, innovative projects, and research work [10]. Researchbased education is a rational, deductive method to teacher education [11]. Research-based professional development practices involve self-study, reading research, reflection, and conducting research [12]. Other online professional development (OPD) policy approaches suggest large scale personalized upskilling and reskilling in communities of practice with the help of open education and massive open online courses [13]. Apparently, there is a dearth of evidence on teacher professional development programs aiming at the integration of XR technologies in education. Teachers in all levels and subjects can utilize these emerging immersive technologies to enhance students' interest and increase engagement so as to improve cognitive outcomes. In this study we present the design, development, and pilot evaluation results from an in-service teacher online professional development program on AR and VR linked with research activities.

The current study is structured as follows: Section 2 delineates the theoretical background on immersive education, its benefits and the state of teacher professional development. Next, the utilized context and involved course activities and materials are described in depth. The research goal and the data collection methods follow in Section 4, while the results are reported next, organized in three identified subtopics. The concluding section contains practical recommendations, limitations, and directions for future research.

\section{Theoretical Underpinnings and Related Work}

VR creates a synthetic, digital created environment, completely separated from the physical surroundings, where the user can interact in intuitive ways [14]. VR can be accessed both by standard computing devices and specialized head-mounted displays or headsets. In the context of this study under the term VR we include virtual worlds, 360-degree spherical videos, and immersive VR supported by systems and devices of all spectrums (i.e., tethered or stand-alone, with three or six degrees of freedom) and prize range. AR merges the physical space with the virtual information by projecting digital, multimedia, computer-generated content onto the actual physical environment that can be viewed through hand-held or wearable devices such as glasses [15]. Although there is no unique definition of MR in the literature, it can be considered either as a superset or as an interactive version of AR technology with standalone wearable headsets $[3,16]$. AR and VR have the potential to offer significant educational benefits related to embodied cognition [17]. VR enables of sense of immersion, the cognitive "teleportation" to a remote or imaginary world and creates the psychological phenomenon of presence, the natural feeling of being there creating the illusion of non-mediation where technology is no longer noticeable [18]. In other words, users do not notice the existence and interference of technological equipment. AR and VR activate episodic memory, the human ability to store long-term complete personal experiences in their multimodal tempo-spatial contexts in addition to the semantic memory of concept-related knowledge [19]. Educational interventions triggering episodic memory increase retention and facilitate in-depth learning [20].

\subsection{Pedagogical Value of $A R$ and VR-Impact on Student Performance}

Instructional methods for AR-based education can be organized in a taxonomy with categories of different pedagogical underpinnings from simple to complex, from passive to active learning and from teacher-defined to student-centered learning [15]. Hence, $\mathrm{AR}$ can be used for visualization, activation, cooperation, immersion, experience, and autonomous production [15]. AR can elicit positive emotional effects on students' interest, attention, participation, motivation, satisfaction, collaboration, creativity, and innovation especially when combined with the element of enjoyment and fun [21]. AR can improve 
learning achievement in student-centered approaches such as problem-based learning in both science, technology, engineering, and mathematics (STEM), and humanities, arts, and social sciences (HASS) subjects [21,22].

Desktop-based VR classroom applications can enhance both attendance-based and distance K-12 education in social VR platforms $[17,19,23]$. VR is becoming increasingly important in many fields such as health care and in the architecture, engineering, and construction sector [3,24]. VR benefits can be traced in the cognitive, affective, and social domains [19]. Students who have followed VR-supported instruction have successfully achieved better outcomes than their counterparts in traditional (lecture-style) formats [17,25]. Viewing 360, spherical immersive VR videos can increase attention and teachers' professional noticing capabilities [18]. Teachers applying VR for teaching can focus on essential factors to assess student performance in education such as learnability, motivation, creativity, and interaction [26].

\subsection{Teacher Training in $A R / V R$}

There is a scarcity of evidence related to online teacher continuous professional development (TPD) programs for AR-supported education [21]. One TPD program integrated AR with core STEM curricular ideas with problem-based and inquiry-based learning in an effort to transform classrooms and/or laboratories into smart-learning environments [27]. Another TPD project attempted to turn teachers into AR developers [28]. In higher education, the CVRriculum initiative has demonstrated that embedding VR in undergraduate courses assignment is feasible provided sufficient resources [29]. As public desktop-based VR systems and platforms have been widely available, more elaborate teacher training schemes and recommendations have been articulated according to learning theories such as social constructivism, situated learning, and community of inquiry $[30,31]$. Successful TPD in virtual worlds needs a solid pedagogical rationale, persistent scaffolding, and technical support taking into account participants' prior experience or lack thereof. In the context of distance education, synchronous online meetings in visually stimulating spaces are beneficial for participants' motivation and sustained engagement [32]. In the context of teacher education, immersive VR classroom simulations have been utilized to facilitate pre-service teacher students' practicum to alleviate the pandemic's restrictions and physical education limitations [33] and to assess teachers' preparatory experiences in immersive environments by evaluating and reflecting on $360^{\circ}$ videos [18].

\section{Teacher Online Professional Development Program on AR and VR}

\subsection{Instructional and Learning Design}

Following the specifications of the Pedagogical Institute of Cyprus' teacher digital competence development project, the eight-week teacher OPD program "Augmented and Virtual Reality in Teaching and Learning" was developed by the authors. The dual aim of the program was (a) to empower teachers of every level and discipline to use, modify, and reuse existing resources, and environments in a pedagogically-informed manner and (b) the implementation of simple technological applications with AR and VR tools for educational scenarios. After the completion of the TPD, teachers would be able to:

- Define the concepts of AR and VR and describe their characteristics, advantages, and limitations;

- $\quad$ Select learning objects from digital libraries, applications, and immersive environments and incorporate them into their teaching;

- $\quad$ Operate with ease simple AR and VR applications;

- Implement innovative teaching scenarios using AR or VR;

- Organize collaborative AR- or VR-supported learning scenarios thrusting students into the role of co-producers;

- Evaluate and reflect on their practice assessing the results from learning scenarios research.

In the initial course design, a blended learning format was foreseen with both online and classroom-based modules and sessions. However, the program was adapted for fully 
online delivery due to the pandemic-related restrictions of co-located events in physical spaces. In this context, the program's duration was prolonged to accommodate participants' needs. The successful completion of the program awarded participants with two European Credit Transfer and Accumulation System (ECTS) points. One ECTS point corresponds to $25 \mathrm{~h}$ of study time and is recognized internationally in higher education studies [34].

The program was structured in four modules (Table 1). Module 1 "AR and VR in Education" empowered teachers to embrace AR and VR, study good practices, and reflect theoretically on the usefulness and applicability of immersive technologies in their classes. The next two modules "Digital storytelling with AR" and "Inquiry-based learning with VR" enabled participants to experience and interact practically with AR and VR through virtual field trips. In this way, participants were equipped for the design and implementation of a practical, collaborative research-based scenario with AR or VR, the epicenter of the program's final module [8]. In the intermediate modules 2 (AR) and 3 (VR) a flipped learning approach was followed, where self-study and individual, flexible work proceeded an online workshop.

Table 1. Activities, layout, and study effort (in study hours) of the AR/VR OPD program.

\begin{tabular}{|c|c|c|c|c|c|}
\hline \multirow{2}{*}{$\begin{array}{l}\text { Learning Activities and } \\
\text { Assignments }\end{array}$} & \multicolumn{4}{|c|}{ Program Module } & \multirow{2}{*}{ Total (Study Hours) } \\
\hline & 1 & $2(\mathrm{AR})$ & 3 (VR) & 4 & \\
\hline Interactive video lectures & 0.75 & 0.5 & 0.5 & 0.25 & 2.25 \\
\hline Online meetings/workshops & 2 & 3 & 3 & 2 & 10 \\
\hline Study of material & 2 & 2 & 2 & 1 & 7 \\
\hline Self-assessment & 1 & 0.5 & 0.5 & & 2 \\
\hline Peer review & & & & 1 & 1 \\
\hline Critical forum discussions/reflection & 6 & 2 & 2 & 1 & 11 \\
\hline Hands-on practice & & 2 & 2 & 3 & 7 \\
\hline Research project & & & & 10 & 10 \\
\hline Total (study hours) & 11.75 & 10 & 10 & 18.25 & 50 \\
\hline
\end{tabular}

The AR/VR OPD program featured a research-based and pedagogically-informed curriculum. Educators were encouraged to explore authentic research content and to apply a plethora of critical-reflective, creative, and cooperative learning strategies through the meaningful integration of AR and VR. Given the timeframe, AR has been coupled with digital storytelling, while VR with inquiry. It is worth noting here that in terms of VR both immersive VR applications using head-mounted displays as well as desktopbased VR environments such as 3D virtual worlds were included. Each approach was explored, demonstrated, and applied so that educators could develop their pedagogy and technology knowledge. Digital storytelling allows learners to co-create artifacts [35]. AR enriches digital storytelling options especially in humanities, social sciences, languages, and interdisciplinary HASS subjects [36]. On the other hand, inquiry-based learning in VR environments is suitable for the autonomous, self-directed, and cooperative of students of all ages, especially in STEM related disciplines [25]. Since this OPD program was horizontally offered to K-12 educators of all disciplines, it was crucial to ensure its content is relevant, inclusive, and applicable in multiple school settings and for all student age groups.

Teachers' performance assessment was tripartite and immediately linked with the classroom application research as its most important component, accounting to $60 \%$ of the total grade. The quality of other completed learning assignments was the second highest component making up 30\% of the final grade. Finally, engagement, effort, and extra work in the two synchronous online workshops attributed an additional $10 \%$. Teachers were required to score at least $50 \%$ in each component to complete the program successfully.

\subsection{E-learning Development for OPD}

The AR/VR OPD program was implemented fully online in a blended fashion that combined synchronous and asynchronous e-learning. Synchronous meetings took place in Microsoft Teams. Educational materials and assignments were organized in a Moodle learn- 
ing management system (LMS). Moreover, several other collaborative web platforms were utilized such as Padlet, Edupad, Google Drive, Kahoot!. The layout of the digital learning environments, written communication texts, and educational materials followed Cyprus' Pedagogical Institute guidelines for user friendly interface and aesthetically pleasing graphical design intending to attract attention and encourage engagement without unnecessary extraneous cognitive load. Authors made a conscious effort to integrate playful elements so as to foster a relaxed and joyful emotional climate [37]. For instance, metaphors were utilized in the title and accompanying visual elements of all course activities: study of material was coined "deep-dive into AR/VR", while self-assessment quizzes as "oasis of AR/VR knowledge".

The program featured conventional and flexible e-learning materials as well as special resources to facilitate its research-based approach. A study guide provided all information and participation logistics to teachers. A weekly study schedule typically consisted of the following activities: watching of video lectures, taking a self-assessment quiz of randomized questions to verify content comprehension, and conducting individual and group activities in digital platforms, openly shared to facilitate peer learning. Twenty-one video lectures were produced in total. Active learning was scaffolded with templates, examples, sources of inspiration, and links to teacher communities. Teachers are encouraged to collect data, reflect, construct arguments, and make critical reflections and decisions about the suitability of AR and VR to facilitate learning. For instance, immersive VR should not be the prime technological choice in the educational scene unless scenarios involve situations, locations, procedures, and activities that are either dangerous, impossible, inconvenient, or too expensive to conduct in the physical world [38]. In this case, VR can be integrated into teaching for four prime objectives in stages of increasing complexity: Perception/Stimulation, Interaction, Immersion, and Telepresence [14].

Research-based activities were organically interwoven into the curriculum in the form of studying and reflecting on selected literature and on participating in the enrichment of an open collaborative database of good practices and research studies. The authors compiled an initial collection of good practices and relevant AR/VR pedagogical applications; however, one of participants' task was to locate and propose new, noteworthy resources related to their specific domain. A separate guide with instructions was offered for the final, classroom application research. Participants had complete freedom to make choices concerning the technology, the pedagogical approach, the instructional design of their application and research. After the classroom application and research data collection, teachers were prompted to share lesson plans and materials in the national repository of open education resources [39].

More specifically, the program featured the following activities: The first module on AR and VR in education started with three open, collaborative asynchronous activities: selfintroductions, a SWOT self-diagnostic assessment, and a critical reflection on knowledge, skills, and experiences with AR and VR environments. Then, the inaugural synchronous web meeting took place. There, all aspects of the program were discussed and the pedagogical contract was agreed upon. Participants continued with their own self-directed study of video lectures and selected short text. The module concluded with a self-assessment quiz where participants can verify their comprehension. The next two modules on AR and VR respectively had a similar flipped-classroom structure: video lectures, tutorial videos, and short readings were provided first with the self-assessment quiz. Then came the time for application and experience: participants received elaborated instructions and worksheets to install specific apps, browse specific good examples, and prepare for the next activity, the practical synchronous online workshop. In the two online workshops, participants worked with step-by-step scenarios to implement a simple AR/VR environment for a pedagogically-driven intervention, namely storytelling with AR and discovery with VR. The final module was focused on the classroom application research in three stages: first, all draft designs underwent open peer review to maximize idea exchange and cross-fertilization. Teachers applied their finalized plan in the classes. Finally, all projects 
and preliminary results were presented in the concluding online meeting, uploaded also to the national repository. Participants also reflected in a critical discourse on their personal journey with immersive technology in relation to their initial fears, newly constructed skills, and aspirations for the future. More details, samples, and snapshots from the mentioned materials and activities are included in the Supplementary Material S1.

\section{Methodological Framework}

In this study, the guiding research question was, "What were teachers' perceptions and reflections from their participation in an online professional development program on AR and VR in education?" The overarching goal was two-fold: first, to diagnose what degree the intended learning outcomes serving the teachers' needs can be achieved within the selected curriculum and second to detect eventual areas and issues for improvement in terms of pedagogy, technology, and resources in the quest to achieve a transformational experience of high quality and higher order cognitive abilities $[40,41]$. Participants were fourteen K-12 teachers that enrolled in the program during April-July 2020 after a call for volunteers. They were from kindergarten, elementary schools (primary education), middle, and high schools (secondary education). Their composition was female (57\%), male (43\%).

A mixed method research approach was deployed on a case study combining quantitative and qualitative data collection and analysis. The case study was conducted in a natural setting as a quest to capture and interpret teachers' views and construct an indepth understanding of the investigated intervention and its effects. The main research instruments and data collection methods were the following: diagnostic assessment, communications, online behavior observation, personal diaries, formative and summative assessment questionnaires, and focus groups.

(i) Diagnostic assessment followed the strengths-weaknesses-opportunities-threats (SWOT) framework: Participants recorded their perceived strong and weak characteristics in relation to the program's content and layout, as well as their eventual fears or insecurities and opportunities for future practice. After their replies were categorized, they were discussed during the pilot program's inaugural meeting. After their processing, the learning contract was co-decided;

(ii) Communications: During the program frequent written communication took place in discussion forums, public, and private e-mails (e.g., announcements, instructions, links, feedback). Teachers were instructed to report issues, doubts or problems directly, as soon as they encounter them;

(iii) Online behavior observation: During the program participants' activity in the LMS was monitored on weekly basis to ensure their smooth access and engagement with the content. In addition, during the online meetings and workshops, their reactions and opinions were recorded and decoded thematically;

(iv) Diaries: During the program's duration, participants were encouraged to record and reflect on their experiences with the included resources and activities. They had the choice to keep their personal diaries either in private or in public;

(v) Questionnaires: The questionnaires were anonymous and consisted of five sections: structure and organization, educational content and activities, effectiveness, interaction, skills, participation, general impressions and comments. Each section contained closed and open questions. Closed items examined teachers' agreement with a five-level Likert scale ranging from "fully disagree" to "fully agree". To ensure the questionnaires' face and content validity, they were submitted to a panel of three pedagogical experts from two different universities who provided constructive feedback and confirmed their appropriateness;

(vi) Focus groups took place online after the completion of all formal educational activities. Each group consisted of 4 to 6 people. During the meetings, researchers listened to teachers' opinions to trigger questions organized as a semi-structured interview. The main points raised and discussed during the focus groups were summarized at the end of each meeting for verification or amendment by the participants. 
In this case study, multiple data sources and tools were used to guarantee the validity of the results. Triangulation was achieved as the comparison of many sources of evidence to ascertain the accuracy of information or phenomena. Methodological triangulation uses a plethora of approaches to explore the same issue or phenomenon [42]. Triangular techniques in social sciences try to map out the abundance and intricacy of human behavior by studying it from more than one point of view [43]. The incorporation of diverse data in the study ensures their triangulation by detecting possible contradictions and unidentified effects. As far as the reliability is concerned, researchers updated results to be in line with teachers' expressed opinions without any misconceptions. In case of doubt or ambiguous statements, further explanations were requested.

\section{Results}

To detect and describe in-depth teachers' perceptions and reflections from their participation in the AR/VR OPD program, presented evaluation findings from data triangulation are categorized under three major topics: (i) educational content and activities effectiveness, (ii) engagement, interaction, and performance, (iii) overall user experience and feedback. The following abbreviations associated to the research instruments and data sources were used (Table 2).

Table 2. Codification of research instruments.

\begin{tabular}{cc}
\hline Research Instrument & Abbreviation \\
\hline Diagnostic assessment & SWOT \\
Communications & Comm \\
Online workshop observation & Obs \\
Reflective diary & Diary \\
Formative questionnaire & FQ \\
Summative questionnaire & SQ \\
Focus groups & FG \\
\hline
\end{tabular}

\subsection{Educational Content and Learning Activities Effectiveness}

The educational content included several types: introductory video lectures, visualized and interactive presentations, infographics, databases, reading material from external Open Educational Resources (OER), such as selected research studies, Technology Enhanced Learning (TEL) activities, bibliographic references, and suggestions for additional, voluntary study. Participants appreciated highly the program's polymorphic content and activities. Specifically, summative questionnaire (SQ) results confirmed that 75\% argue that video lectures explained and demonstrated adequately the concepts, and skills of each module (Figure 1). All participants (100\%) agreed that instructions were clear and course's summarizing elements and visuals enhanced their interest. Moreover, $88 \%$ found the diverse content understandable and relevant to program's purpose and aims.

Specifically, participants mentioned that the material "included both visual and auditory material" (FQ), "very informative-simple videos" (SQ), with "very interesting video lecturing about digital storytelling and AR" (SQ). Other noted that there was "so rich and interesting content" (FQ). It was also mentioned that "the instructions of each learning module were well-understood with absolute clarity and accuracy" (FQ), it was "generally very understandable" and that was possibly the reason they believed that the content "could be used without significant help from the educator" (FQ). In relation with course's graphics, they found that "the images of the module were of particular interest" and caused their "attention and interest" (FQ). Authors made a conscious effort to include data from multiple sources so as not to confine educators in silos of thinking of academic or other nature. In addition, while they seemed "very satisfied with the summary presentation elements, such as tables and diagrams" (FQ). The objectives and the synopsis, contained systematically in each video lecture pleased them the most (FG). Specifically, it was stated that "the summary and conclusions were very understandable and helped us better understand the purpose of each subsection, but also why it contained the specific tools, methods, and activities" (FQ). 
Submitted improvement requests lead to instant content modifications. For instance, two video lectures were considered theoretical: "more clear links with practical implementations in the classroom are needed" (Diary), "the video mentions the design and preparation stages but I believe more support is necessary for the actual application" (FQ). Based on teachers' formative feedback, authors implemented a series of changes to meet their expectations. In terms of technology, some video lectures were initially produced with synthesized, AI-generated voice narration. Teachers mentioned that the "narrator's voice sounds robotized" (FQ, FG). Hence, video lectures were reproduced with authors' voices. Other minor changes were the more frequent parallel use of English and Greek technical terms and the integration and analysis of additional examples in two theoretical video lectures.

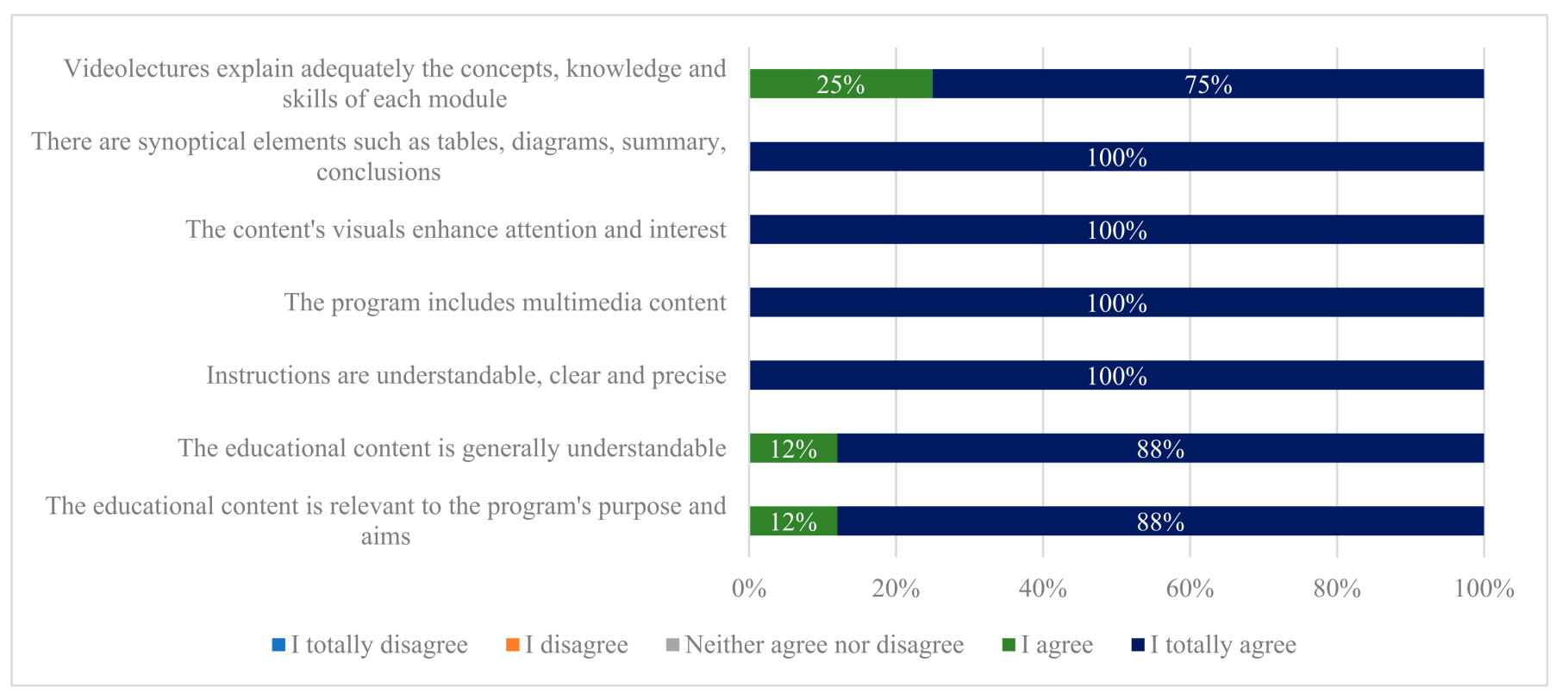

Figure 1. Participants' evaluation of the educational content and activities (SQ).

Specific activities were particularly satisfying to teachers, e.g., "the inaugural online meeting activity was very informative" (Diary, FG). Snapshots from learning activities are depicted in Figure 2. Research-based activities were quite new to teachers, but they were well received. Examples and good practices accompanied every immersive technology or presented advantage. After that, participants were able to consume research studies in the program's repository, discover new ones and come up with ideas to test in their own practice (FG).

Examining the effectiveness of each of the OPD course's components, the following results were recorded. Teachers enjoyed greatly the video lectures in terms of quantity, duration, content, and structure (Figure 3). Hence participants watched them with great interest and diligence (Obs). They noted that "video lectures were extremely useful" in their pressed time since they "explained shortly each concept, offered information, and examples we could further explore in our own time and leisure" (SQ). They enjoyed in particular that "the video could be stopped, so as to browse each slide, its narration so as to understand each new idea at your own pace" (FQ), "to search the links and examples and to go back and forth if you needed to remember something and continue" (SQ). The above elements seem to have alleviated participants' fears concerning the comprehension of new, unfamiliar concepts and technologies (SWOT). 


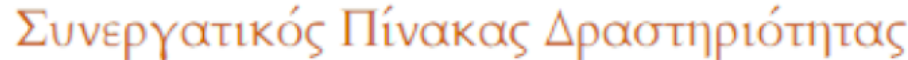

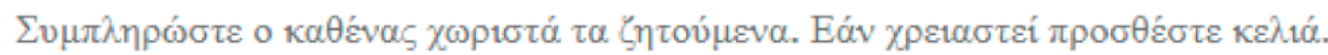

\begin{tabular}{|c|c|c|}
\hline & \multicolumn{2}{|r|}{ SWOT ANALYSIS| } \\
\hline Ovopa: & 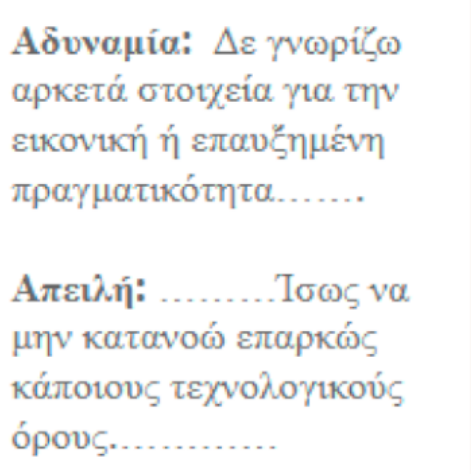 & 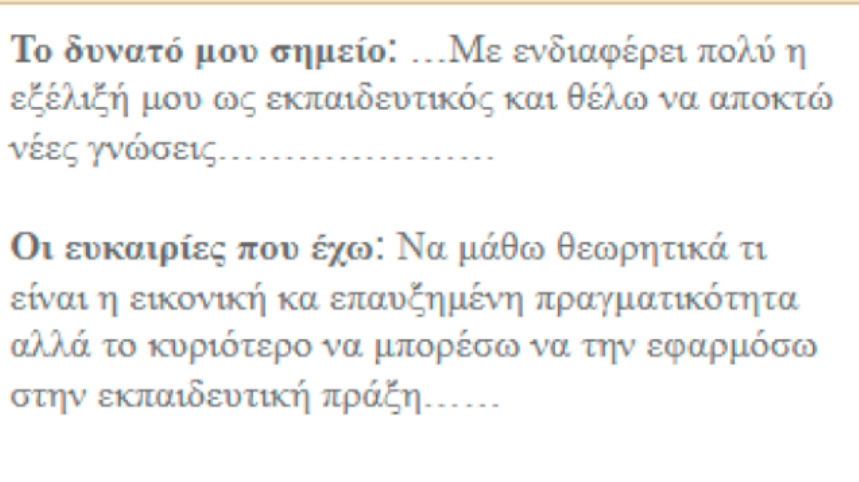 \\
\hline Ovopa: $17=$ & 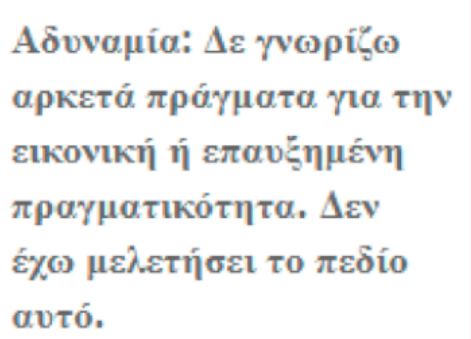 & 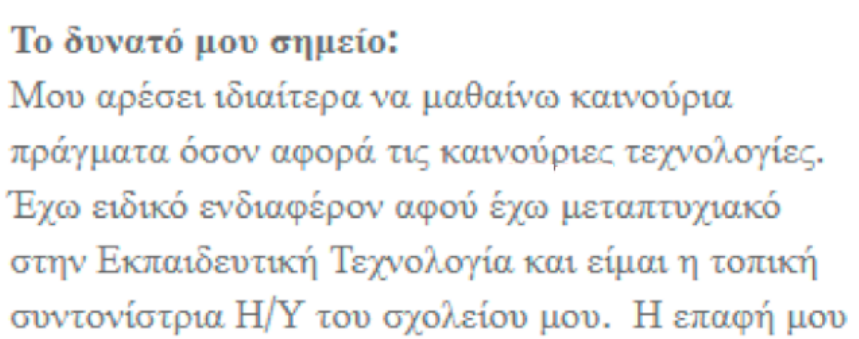 \\
\hline
\end{tabular}

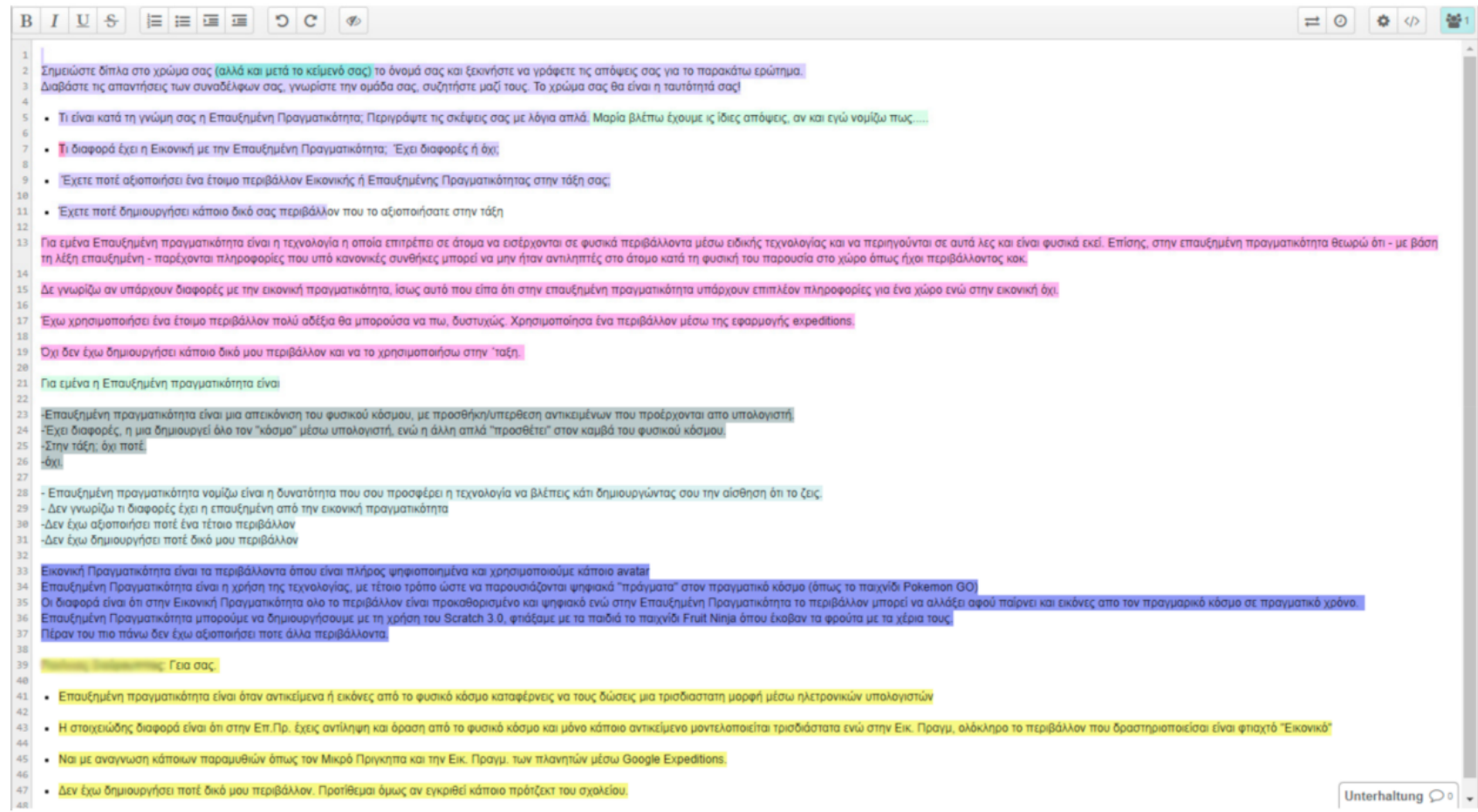

Figure 2. Screenshots from two collaborative activities in web-based environments. 


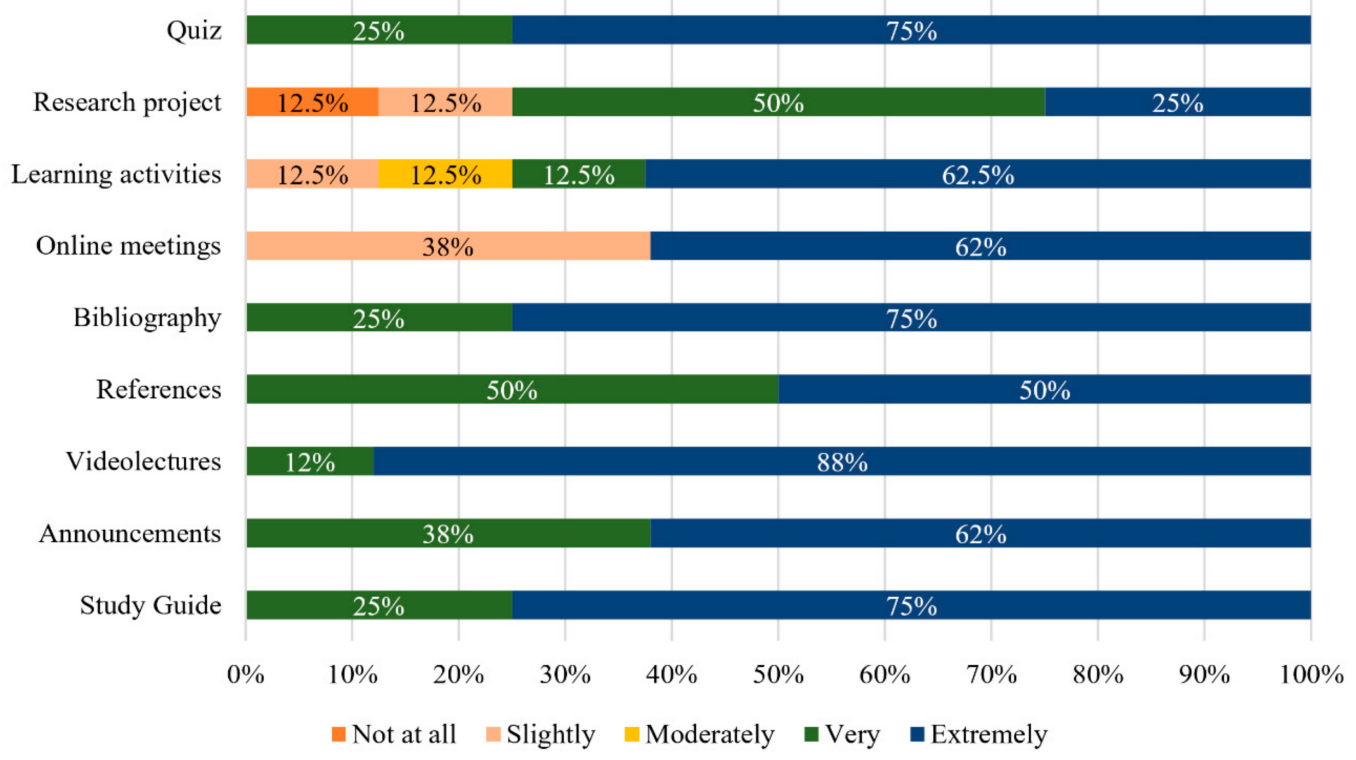

Figure 3. Participants' evaluation of the effectiveness of the program's components (SQ).

One educator (P7) had difficulties in the comprehension of the concepts of AR and VR: "I am perplexed by the presentation of so many concepts, some of them hard for beginners and their inclusion in the good practice database. Unfortunately, I can't study on my own all these good practices. [] We are accustomed to being instructed, being explicitly guided by an instructor in physical or online presence" (SQ). "In an unfamiliar training domain, it takes a lot of time to extract elements so as to create content of pedagogical value, something which poses a serious challenge for in-service teachers" (Diary). Another participant (P11) conceded that "due to the extenuating circumstances and time pressure" he "could not study extensively all sources, references, and links; however, all of them were very useful and necessary" (SQ). This confirmed their initial fears of lacking available personal study time (SWOT). Not being able to catch up with the program's weekly schedule created a cascading effect to some participants who missed some essential online meetings and could not complete the classroom research application in the available time.

\subsection{Engagement, Interaction and Performance}

The consensus of participating teachers agreed that the course encourages knowledge creation through discovery and creative practice and offers ample opportunities for selfassessment, reflection, and critical thinking through multiple cognitive representations and arguments (Figure 4). Eighty-eight percent concurred that the program promoted interactive, hands-on learning opportunities. One participant (P5) wished interestingly for more informal activities in collaborative web tools (in contrast to formal, individual LMS assignments) as "short cooperative activities encourage interaction among us" (FQ). Attitudes towards peer communication and active engagement were less enthusiastic with $38 \%$ avoiding agreement or disagreement. This effect can be attributed to a more flexible approach towards teachers' work due to their workload in the pandemic's unprecedented circumstances. Excessive flexibility can potentially undermine the communal practice and liveness of the asynchronous discourse (Obs): A cohort's program advancement in relative synchronicity is advantageous as peer progress and support are essential motivational factors (FG).

Initially, interaction with participants was achieved through collaborative activities. The interface with educational environments constituted a familiarizing process with AR and VR tools (Obs). Teachers' overall engagement and performance was quite satisfactory, especially in the final research project. The research emphasis of this practical activity is reflected in the template layout which contains sections such as abstract, learning design, materials, implementation, reflection, discussion. As it is evident, the template has several similarities with academic manuscripts. One critical success factor was the active partic- 
ipation in all synchronous hands-on e-practice sessions and activities with specific AR applications and VR platforms. Another observation was the usefulness of peer feedback during the project design phase. Participants were encouraged to post openly an intermediary version of their lesson plan and early prototypes of their resources, visible to the whole group. This allowed for fruitful peer exchanges to emerge and open instructors' feedback with practical remarks.

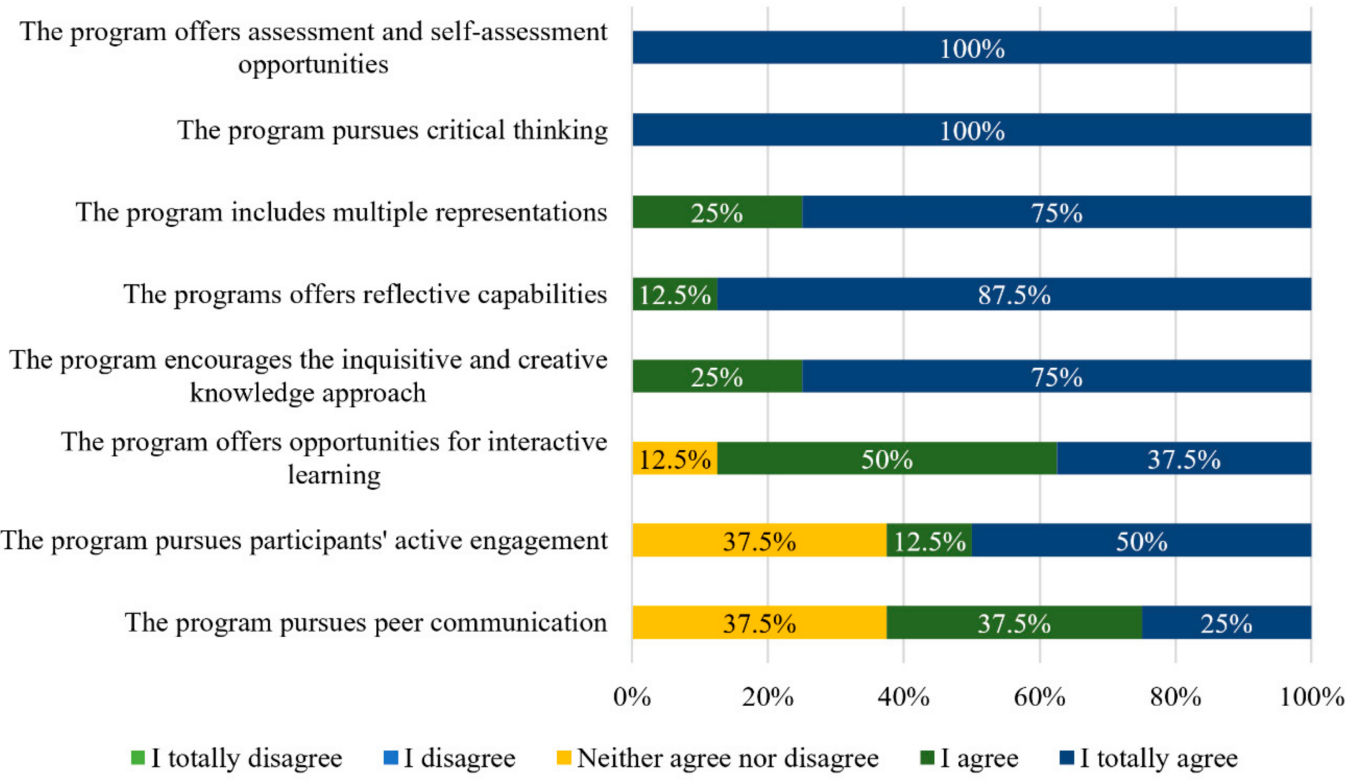

Figure 4. Participants' evaluation of the program's pedagogical orientation (SQ).

Concerning the class research project, most teachers mentioned that "they would prefer to have trainers' support with immediate interaction and feedback in a physical space" (SQ). In the fully distance setting, "it would be useful to have a ready, fully developed scenario for modification" (SQ). They added that participants need "supervision/guidance because educators will have many questions" (FQ, FG). During focus groups, the conclusion was reached that due to the existence of several tools and applications, it would not be appropriate to impose one concrete scenario template or direction for all. Instead, trainers opted to provide personalized support for each scenario according to each educator's decision, students' needs, school's equipment, and infrastructure.

Following the guidelines, participants' application, and research projects lead to interdisciplinary implementations. Linear quests were adopted in scientific and computer science disciplines such as physics, chemistry, and coding/programming. Digital storytelling both in VR and AR was popular due to active role that pupils can play in their design and development. For example, first grade elementary school students painted to learn numbers from 1 to 10. They imagined and visualized numbers as flying objects. Through an AR app students scan their paintings and suddenly clouds, birds, and aerostats "come to life" and "float" in the air (Figure 5). To develop their stories, students created scenes in storyboards after they have defined elements such as who (heroes, actors), what/how (plot, action), when, where, why (problem).

Another practice that was observed was the incorporation of AR and VR into larger technology-related scenarios and group projects. For instance, one teacher prompted groups of students to create their own 3D scenes in a social VR environment or in AR to promote and introduce their science assignments. Others created an awareness raising campaign for younger students about global and local environmental challenges where students scanned trigger images to access AR resources, e.g., videos and quizzes. 


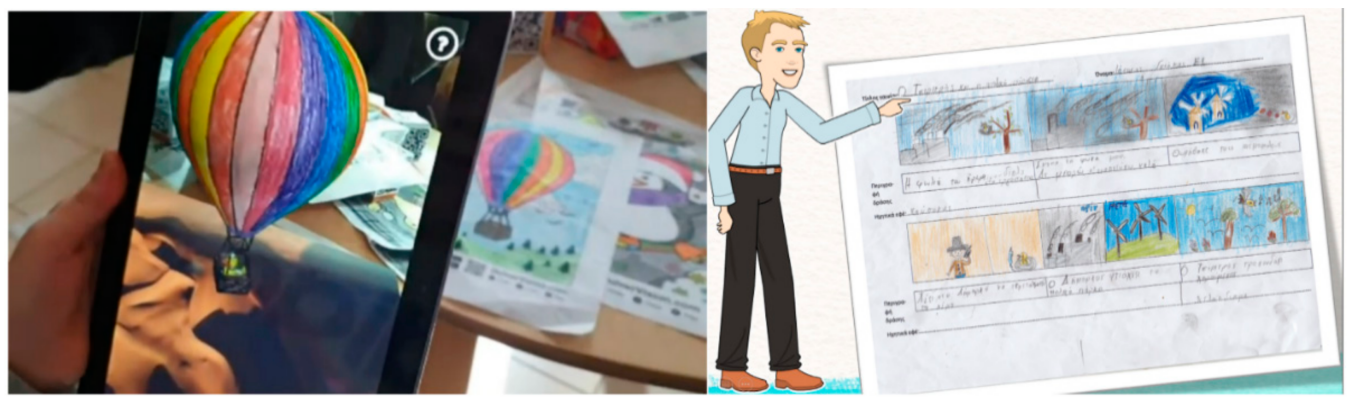

Figure 5. Snapshots from AR projects with digital storytelling: actual application (left), storyboard (right).

\subsection{Overall User Experience}

The user experience evaluation yielded positive results. The overwhelming majority of participants found the utilized digital learning environments and platforms accessible from multiple devices and user-friendly (Diary, FQ). Consequently, access and navigation of the educational content and activities were seamless (Obs). As displayed in Figure 6, teachers approved the program's structure and organization. Both the program's study guide and the project's instructions provided clear guidance and information of what is expected, when, and how (FG). As a result, $82.5 \%$ concurred that the program fulfilled their needs and aspirations (SWOT, FG). A few mentioned the physical presence of trainers that is "necessary for such specialized themes" (FQ), a comment that points out their desire for more synchronous, teacher-led activities. The program's goal and intended outcomes were sufficiently "clearly articulated and corresponding to the module's content" (diary).

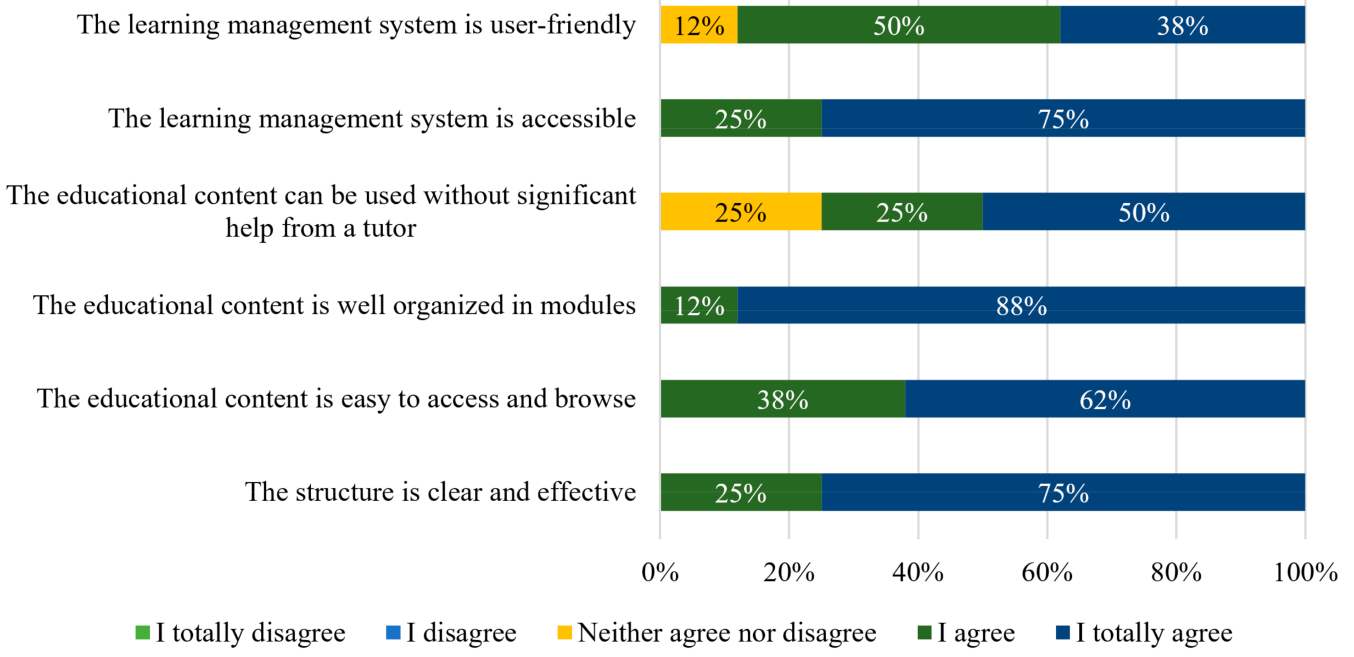

Figure 6. Participants' user experience evaluation (SQ).

Overall, $83 \%$ agreed or agreed fully that the program met their expectations (Figure 7). They found it "interesting and relevant to my teaching practice" (SQ). They were "in general satisfied with the educational material" (FQ, FG) pointing out that "my participation helped me think of ways to improve teaching" (FG); therefore, $83 \%$ "would recommend this program to other colleagues" (SQ). Others mentioned that "I am enthusiastic with the content and the plethora of new information contained. I acquired new experiences and challenges" (Obs), "so far I have found the course extremely interesting" (Comm).

When asked what they enjoyed in the program, teachers provided various answers regarding components of the program: "The fact that I learned and experimented with new exciting practices" (FG), "video lectures and each module's layout" (SQ), "plenty of sources and references for deeper research" (FQ), "the clear structure and its sequentially aligned content" (FQ), "new experiences that opened up new challenges" (FG), "online meetings with instructors" (diary). Reversely, when asked what they disliked or inhibited their 
participation, teachers mentioned pressing time constraints and class time with instructors: "the time wasn't appropriate for me to study as much as I should, the duration was too condensed. I would like to have more time" (SQ, FG). "Preparation time can become a nightmare if you attempt a too complex scenario" (FG). "It would be much better if we had the opportunity for more teleconferences" (FQ, FG).

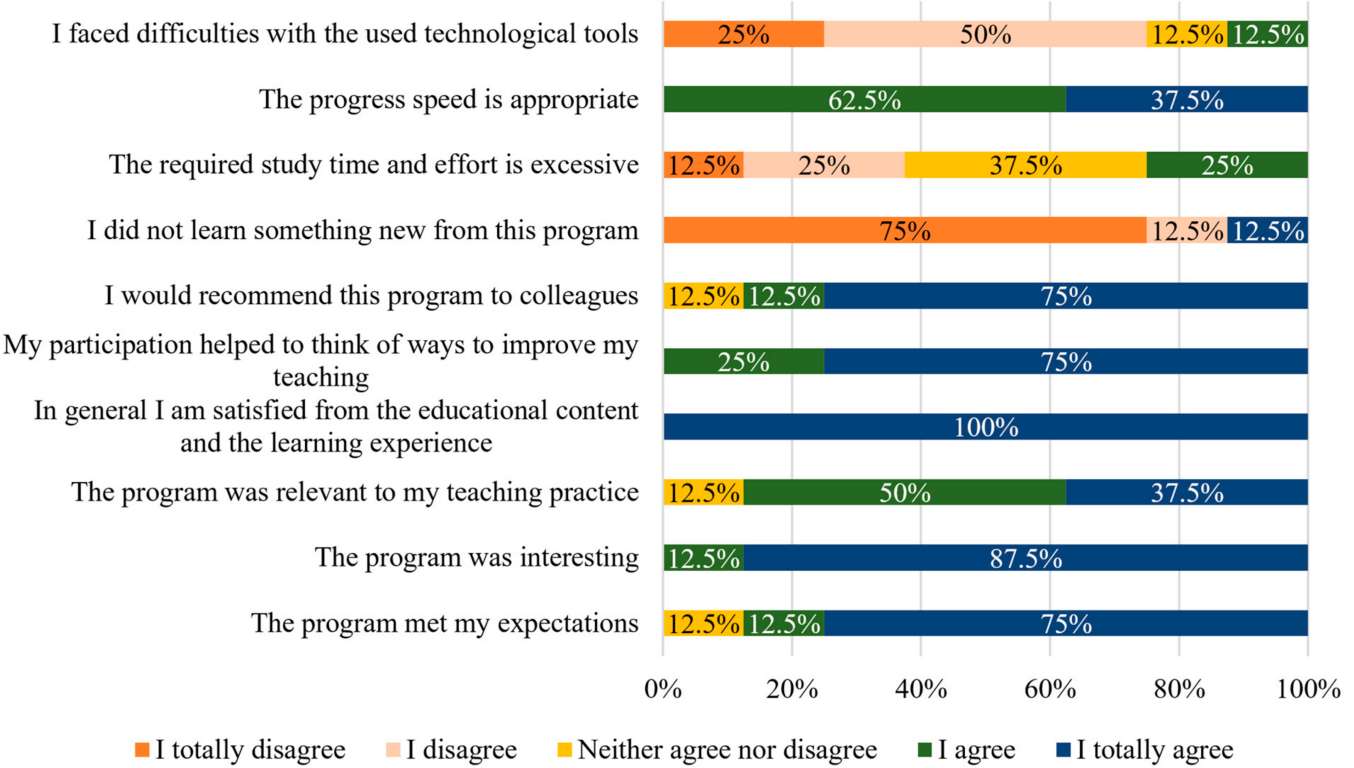

Figure 7. Overall participants' experience evaluation (SQ).

Regarding the impact of AR/VR projects on students, teachers reported that students would like to use and experience them more often in their classes because they can see immediately the results of their actions. In addition, their creations "came to life" so the element of surprise became apparent. One pupil in elementary education described it as "magical". To them, this process was perceived as play and thus they displayed sustained enthusiasm. Educators reported in their observations that "student cooperation was significantly better and more effective in comparison to other times" (FG). Pupils' curiosity, initiative, and agency increased to achieve results that they considered satisfactory. They exchanged thoughts and ideas with greater frequency and ease on the studied subject. As a result, they drew very high levels of satisfaction from their engagement.

\section{Conclusions}

In this study the design, development, and evaluation of an OPD course on AR and VR in teaching and learning for in-service teachers was presented. The study's main goal was twofold: (a) to diagnose to what degree the intended learning outcomes serving teachers' needs can be achieved within the proposed curriculum and (b) to detect eventual areas and issues for improvement in terms of pedagogy, technology, and resources in the quest to achieve a high quality, transformational experience towards higher order cognitive competencies. Indications of this trajectory were participants' optimistic statements that VR and AR opened up new educational horizons for novel experiences and challenges. Participants set goals and approached emerging challenges according to their developed self-efficacy with the new immersive technologies. Participants with a stronger interest in the activities were more committed and deeply connected to their own motivations [44], and as a result achieved superior levels of performance and satisfaction.

This pilot study has some notable limitations: The program was designed and implemented during a turbulent time when COVID-19 disrupted all physical activities in the educational process. Therefore, this had a serious impact on teachers' schedule, time, and preparation. This unique event upset teachers cognitively and emotionally. As a result, all foreseen physical meetings of the OPD program took place online. Moreover, in 
June 2020, after three months of remote emergency teaching, teachers were called by their supervisors to return to classroom teaching under strict sanitary restrictions and protocols. The aforementioned events lead to decreased participation due to school obligations. Another limitation of the current study is the limited sample size that cannot be rendered representative of all targeted schoolteachers.

Lessons learned during this program, lead to the following practical implications and recommendations for the practitioners and similar OPD programs. In terms of educational content production, a balance is recommended between available digital resources and self-created materials, e.g., 360 videos. Teachers need to see what is possible and which products of top professional quality are available online while simultaneously realizing the pedagogical and emotional value of teacher-generated content for their own students. In this way, they can lead by example, experiment, and demonstrate the acceptance of eventual imperfect aesthetic or technical results. Total immersion with VR headsets for all students in a physical classroom makes sense only for a limited time. For more elaborated scenarios, a "cycling stations" approach is possible to maximize efficiency of equipment usage, wherein student groups engage and collect information from multiple learning stations in a rotating fashion. Shared VR equipment use raises legitimate sanitary concerns that need to be addressed. Moreover, in school education, several health and ethical issues should be considered and monitored such as the lasting impact on students' mental state, vision, and affective development, as well as data privacy [45]. In distance education contexts, social VR platforms can help teachers overcome the limitations of web-based 2D systems and create the sense of co-presence, overcoming geographical limitations and igniting student's imagination.

Suggested directions and lines of future research include cross-sectional comparative studies on the effectiveness of research-based OPD methods in comparison to traditional forms and in conjunction with other innovative formats such as gamification and massive open online courses $[46,47]$. Longitudinal studies could also reveal the transferability, sustainability and the eventual effects of the systematic application of immersive technologies in primary, secondary and tertiary educational settings.

VR and AR are not educational panaceas; they should be used for specific pedagogical purposes and activities just like any other technological medium when their use can deliver tangible learning advantages to students. Empowered teachers can facilitate deeper learning [48] with enjoyable and memorable experiences in VR and AR through enhanced visualization, interaction with 3D content, engagement, immersion, and co-presence in the direction of creating their own educational holodecks. In this direction, more teacher professional development programs will be required. However, only few, technological skilled teachers will be able to advance quickly without scaffolding and considerable support. For mass teacher onboarding in $\mathrm{XR}$, approaches that encourage peer cooperation in small groups and participation in teacher communities of practice are recommended.

Supplementary Materials: The following are available online at https:/ / www.mdpi.com/article/10 .3390 / computers10100134/s1, Table S1. Complete list of 44 materials and 20 activities of the online teacher professional development program, “The AR and VR in Education”. Figure S1. Slide (VR Timeline) from video lecture 1.2, "Introduction into Virtual Reality (VR)". Figure S2. Final slide (Summary) from video lecture 2.2, "Digital Storytelling in Education". Figure S3. Slide (collaborative learning) from video lecture 3.4, "Pedagogical Applications of Social VR in Education". Figure S4. Snapshot from attachment 1.2 "Good AR/VR Practices in Education". Figure S5. Snapshot from attachment 1.3, "Comparative Table of AR/VR Tools \& Platforms". Figure S6. Slide from activity 1.3, "Inaugural Online Meeting" (Meeting Outline). Figure S7. Snapshot from activity 2.4, "Augment your Teaching!" Instructions. Figure S8. Snapshot from activity 4.3, “Class Application and Research Project" template. Figure S9. Snapshot from attachment 4.1 "Inquiry-based Learning Scenario with VR environments Instructions". Figure S10. Snapshot from the asynchronous learning environment in the Moodle Learning Management System.

Author Contributions: Conceptualization, S.M. and M.F.; methodology, S.M. and M.F.; software, G.F.; validation, S.M., M.F. and G.F.; formal analysis, M.F.; investigation, S.M.; resources, G.F.; data 
curation, S.M.; writing—original draft preparation, S.M. and M.F.; writing—review and editing, S.M. and M.F.; visualization, S.M.; supervision, S.M.; project administration, S.M.; funding acquisition, M.F. All authors have read and agreed to the published version of the manuscript.

Funding: This research was funded by the Cyprus Pedagogical Institute, project 21/2019 "Digital Competence".

Institutional Review Board Statement: Not applicable.

Informed Consent Statement: Not applicable.

Data Availability Statement: Data is contained within the article and Supplementary Files.

Conflicts of Interest: The authors declare no conflict of interest.

\section{References}

1. Kamenov, K. Immersive Experience-The 4th Wave in Tech: Learning the Ropes. Available online: https:/ / www.accenture.com/ gb-en/blogs/blogs-immersive-experience-wave-learning-ropes (accessed on 21 May 2021).

2. Ziker, C.; Truman, B.; Dodds, H. Cross Reality (XR): Challenges and Opportunities Across the Spectrum. In Innovative Learning Environments in STEM Higher Education: Opportunities, Challenges, and Looking Forward; Ryoo, J., Winkelmann, K., Eds.; Springer International Publishing: Cham, Swizerland, 2021; pp. 55-77. ISBN 978-3-030-58948-6.

3. Alizadehsalehi, S.; Hadavi, A.; Huang, J.C. From BIM to extended reality in AEC industry. Autom. Constr. 2020, 116, 103254. [CrossRef]

4. Fernández-Batanero, J.M.; Montenegro-Rueda, M.; Fernández-Cerero, J.; García-Martínez, I. Digital competences for teacher professional development. Systematic review. Eur. J. Teach. Educ. 2020, 1-19. [CrossRef]

5. Michos, K.; Hernández-Leo, D. CIDA: A collective inquiry framework to study and support teachers as designers in technological environments. Comput. Educ. 2020, 143, 103679. [CrossRef]

6. Mostert, M.; Quinn, L. Using ICTs in teaching and learning: Reflections on professional development of academic staff. Int. J. Educ. Dev. Using ICT 2009, 5, 72-84.

7. Falloon, G. From digital literacy to digital competence: The teacher digital competency (TDC) framework. Educ. Technol. Res. Dev. 2020, 68, 2449-2472. [CrossRef]

8. Fragkaki, M.; Mystakidis, S.; Filippousis, G. Work-in-Progress-Design and Evaluation of an Augmented and Virtual Reality Flipped-Learning Course for K-12 Educators. In Proceedings of the 2020 6th International Conference of the Immersive Learning Research Network (iLRN), San Luis Obispo, CA, USA, 21-25 June 2020; pp. 275-278.

9. Mostafa, T.; Pál, J. Science Teachers' Satisfaction: Evidence from the PISA 2015 Teacher Survey; OECD: Paris, France, 2018.

10. Van der Klink, M.; Kools, Q.; Avissar, G.; White, S.; Sakata, T. Professional development of teacher educators: What do they do? Findings from an explorative international study. Prof. Dev. Educ. 2017, 43, 163-178. [CrossRef]

11. Jyrhämä, R.; Kynäslahti, H.; Krokfors, L.; Byman, R.; Maaranen, K.; Toom, A.; Kansanen, P. The appreciation and realisation of research-based teacher education: Finnish students' experiences of teacher education. Eur. J. Teach. Educ. 2008, 31, 1-16. [CrossRef]

12. Maaranen, K.; Kynäslahti, H.; Byman, R.; Sintonen, S.; Jyrhämä, R. Do you mean besides researching and studying? Finnish teacher educators' views on their professional development. Prof. Dev. Educ. 2020, 46, 35-48. [CrossRef]

13. Mystakidis, S.; Berki, E. Participative Design of qMOOCs with Deep Learning and 3d Virtual Immersive Environments: The case of MOOCAgora. In Proceedings of the Can MOOCs Save Europe's Unemployed Youth? Workshop, ECTEL 2014 Conference, Graz, Austria, 16-19 September 2014.

14. Mystakidis, S. Motivation Enhancement Methods for Community Building in Extended Reality. In Augmented and Mixed Reality for Communities; Fisher, J.A., Ed.; CRC Press: Boca Raton, FL, USA, 2021; pp. 265-282.

15. Mystakidis, S.; Christopoulos, A.; Pellas, N. A systematic mapping review of augmented reality applications to support STEM learning in higher education. Educ. Inf. Technol. 2021, 1-45. [CrossRef]

16. Speicher, M.; Hall, B.D.; Nebeling, M. What is Mixed Reality? In Proceedings of the 2019 CHI Conference on Human Factors in Computing Systems, Glasgow, UK, 4-9 May 2019; ACM: New York, NY, USA, 2019; pp. 1-15.

17. Pellas, N.; Mystakidis, S.; Kazanidis, I. Immersive Virtual Reality in K-12 and Higher Education: A systematic review of the last decade scientific literature. Virtual Real. 2021, 25, 835-861. [CrossRef]

18. Gandolfi, E.; Kosko, K.W.; Ferdig, R.E. Situating presence within extended reality for teacher training: Validation of the extended Reality Presence Scale (XRPS) in preservice teacher use of immersive 360 video. Br. J. Educ. Technol. 2021, 52, 824-841. [CrossRef]

19. Mystakidis, S.; Berki, E.; Valtanen, J.-P. Deep and Meaningful E-Learning with Social Virtual Reality Environments in Higher Education: A Systematic Literature Review. Appl. Sci. 2021, 11, 2412. [CrossRef]

20. Fragkaki, M.; Mystakidis, S.; Hatzilygeroudis, I.; Kovas, K.; Palkova, Z.; Salah, Z.; Hamed, G.; Khalilia, W.M.; Ewais, A. TPACK Instructional Design Model in Virtual Reality for Deeper Learning in Science and Higher Education: From "Apathy" to "Empathy". In Proceedings of the 12th Annual International Conference on Education and New Learning Technologies (EDULEARN20), Online, 6-7 July 2020; pp. 3286-3292. 
21. Sáez-López, J.M.; Cózar-Gutiérrez, R.; González-Calero, J.A.; Gómez Carrasco, C.J. Augmented Reality in Higher Education: An Evaluation Program in Initial Teacher Training. Educ. Sci. 2020, 10, 26. [CrossRef]

22. Fidan, M.; Tuncel, M. Integrating augmented reality into problem based learning: The effects on learning achievement and attitude in physics education. Comput. Educ. 2019, 142, 103635. [CrossRef]

23. Vrellis, I.; Avouris, N.; Mikropoulos, T.A. Learning outcome, presence and satisfaction from a science activity in Second Life. Australas. J. Educ. Technol. 2016, 32. [CrossRef]

24. Kyaw, B.M.; Saxena, N.; Posadzki, P.; Vseteckova, J.; Nikolaou, C.K.; George, P.P.; Divakar, U.; Masiello, I.; Kononowicz, A.A.; Zary, N.; et al. Virtual Reality for Health Professions Education: Systematic Review and Meta-Analysis by the Digital Health Education Collaboration. J. Med. Internet Res. 2019, 21, e12959. [CrossRef]

25. Pellas, N.; Mystakidis, S. A systematic review of research about game-based learning in virtual worlds. J. Univers. Comput. Sci. 2020, 26, 1017-1042. [CrossRef]

26. Alizadehsalehi, S.; Hadavi, A.; Huang, J.C. Assessment of AEC Students' Performance Using BIM-into-VR. Appl. Sci. 2021, 11, 3225. [CrossRef]

27. Lasica, I.-E.; Meletiou-Mavrotheris, M.; Katzis, K. Augmented Reality in Lower Secondary Education: A Teacher Professional Development Program in Cyprus and Greece. Educ. Sci. 2020, 10, 121. [CrossRef]

28. Papagianni, M.; Eteokleous, N. Developing augmented reality applications: E-learning professional development training for in-service teachers. In Proceedings of the Society for Information Technology \& Teacher Education International Conference 2021, Online, 29 March 2021; Langran, E., Archambault, L., Eds.; Association for the Advancement of Computing in Education (AACE): Chesapeake, VA, USA, 2021; pp. 910-920.

29. Appel, L.; Peisachovich, E.; Sinclair, D. CVRRICULUM Program: Benefits and Challenges of Embedding Virtual Reality as an Educational Medium in Undergraduate Curricula. Int. J. Innov. Educ. Res. 2021, 9, 219-236. [CrossRef]

30. Nussli, N.; Oh, K. The Components of Effective Teacher Training in the Use of Three-Dimensional Immersive Virtual Worlds for Learning and Instruction Purposes: A Literature Review. J. Technol. Teach. Educ. 2014, 22, 213-241.

31. Loke, S.-K. How do virtual world experiences bring about learning? A critical review of theories. Australas. J. Educ. Technol. 2015, 31. [CrossRef]

32. Downey, S.; Mohler, J.; Morris, J.; Sanchez, R. Learner perceptions and recall of small group discussions within 2D and 3D collaborative environments. Australas. J. Educ. Technol. 2012, 28. [CrossRef]

33. Sasaki, R.; Goff, W.; Dowsett, A.; Paroissien, D.; Matthies, J.; Di Iorio, C.; Montey, S.; Rowe, S.; Puddy, G. The Practicum Experience during COVID-19-Supporting Pre-Service Teachers Practicum Experience through a Simulated Classroom. J. Technol. Teach. Educ. 2020, 28, 329-339.

34. Ferrer-Torregrosa, J.; Jiménez-Rodríguez, M.Á.; Torralba-Estelles, J.; Garzón-Farinós, F.; Pérez-Bermejo, M.; Fernández-Ehrling, N. Distance learning ECTS and flipped classroom in the anatomy learning: Comparative study of the use of augmented reality, video and notes. BMC Med. Educ. 2016, 16, 230. [CrossRef]

35. Smyrnaiou, Z.; Georgakopoulou, E.; Sotiriou, S. Promoting a mixed-design model of scientific creativity through digital storytelling-The CCQ model for creativity. Int. J. STEM Educ. 2020, 7, 25. [CrossRef]

36. Di Serio, Á.; Ibáñez, M.B.; Kloos, C.D. Impact of an augmented reality system on students' motivation for a visual art course. Comput. Educ. 2013, 68, 586-596. [CrossRef]

37. Mystakidis, S. Combat Tanking in Education-The TANC Model for Playful Distance Learning in Social Virtual Reality. Int. J. Gaming Comput. Simul. 2021, 13. in press.

38. Bailenson, J. Experience on Demand: What Virtual Reality Is, How It Works, and What It Can Do; W. W. Norton: New York, NY, USA, 2018; ISBN 9780393253702.

39. Ministry of Education and Culture Photodentro Cyprus. Available online: http:/ / photodentro.pi.ac.cy/ (accessed on 12 February 2020).

40. Mystakidis, S.; Berki, E.; Valtanen, J.-P. The Patras Blended Strategy Model for Deep and Meaningful Learning in Quality Life-Long Distance Education. Electron. J. e-Learning 2019, 17, 66-78. [CrossRef]

41. Fragkaki, M.; Lionarakis, A. Education for Liberation. In Handbook of Research on Transformative Online Education and Liberation; Kurubacak, G., Yuzer, T., Eds.; IGI Global: Hersey, PA, USA, 2011; pp. 198-231.

42. Briggs, A.R.J.; Morrison, M.; Coleman, M. Research Methods in Educational Leadership and Management; Sage Publications: Thousand Oaks, CA, USA, 2012; ISBN 1446200442.

43. Cohen, L.; Manion, L.; Morrison, K. Research Methods in Education, 7th ed.; Taylor and Francis: London, UK, 2013.

44. Wang, C.-H.; Shannon, D.M.; Ross, M.E. Students' characteristics, self-regulated learning, technology self-efficacy, and course outcomes in online learning. Distance Educ. 2013, 34, 302-323. [CrossRef]

45. Christopoulos, A.; Mystakidis, S.; Pellas, N.; Laakso, M.-J. ARLEAN: An Augmented Reality Learning Analytics Ethical Framework. Computers 2021, 10, 92. [CrossRef]

46. Mystakidis, S. Distance Education Gamification in Social Virtual Reality: A Case Study on Student Engagement. In Proceedings of the 11th International Conference on Information, Intelligence, Systems and Applications (IISA 2020), Piraeus, Greece, 15-17 July 2020; pp. 1-6.

47. Boltz, L.O.; Yadav, A.; Dillman, B.; Robertson, C. Transitioning to remote learning: Lessons from supporting K-12 teachers through a MOOC. Br. J. Educ. Technol. 2021, 52, 1377-1393. [CrossRef]

48. Mystakidis, S. Deep and Meaningful Learning. Encyclopedia 2021, 1, 988-997. [CrossRef] 